\title{
Undergraduate Research Abroad: Challenges and Rewards
}

\section{Why Encourage Rese arch A b r o a d ?}

Why should international educators encourage research abroad? The work of the students represented in this Special Volume of Frontiers exemplifies the best of undergraduate research abroad. Their research shows an achievement of one, or all, of the goals international educators typically set for learning abroad: linguistic competence, cross-cultural skills, cultural competence, and disciplinary learning. Research abroad often holds strong incentives for successful student learning. Students choose their own research topics, providing intrinsic motivation to move beyond superficial explorations of their topic. Fulfilling faculty expectations for student learning, whether in the form of a paper, thesis, data collection or ethnographic study provides extrinsic motivation.

The value of disciplinary learning abroad, especially in course-based programs, disputed on home campuses. Undergraduate research abroad can demonstrate that the cultural context of learning enhances the disciplinary knowledge gained. Disciplinary learning in another cultural context can correct culturally-ingrained research biases. Students gain knowledge difficult to capture without the cultural exposure provided by the experience abroad, which informs their work with nuances of first-hand research, moving it beyond the intellectual. Home-campus faculty may be less skeptical of the merits of sending students abroad for disciplinary learning if that experience results in an increase in knowledge or a demonstration of the application of previously gained disciplinary knowledge in a new context.

Developing research skills in an international context means that students must learn how to navigate in another culture. Students must interact with people who are not their peers and who are outside a traditional classroom setting. By approaching organizations and individuals that inform their research, students learn much about the workings of the culture. And success in one attempt to navigate a host-culture can lead to success in further attempts. For the student-researcher, persistence is necessary because their research goal depends on successfully gaining access to the information they require. Cross-cultural skills are the tools that enable student-researchers to accomplish their goals and finish their projects. 
In order to achieve this in non-English language locations, students must develop a certain level of linguistic competence or, if using an interpreter, basic forms of communication in the host language. They must develop these competencies not only in everyday topics, but also in their fields of research. How will they ask about their topic if they do not learn some of the vocabulary? How will they obtain the help or information they need if they cannot ask people for it in appropriate forms? Since a research project typically requires a number of weeks to complete, student-researchers are likely to use these linguistic skills on an on-going basis. As a result, the linguistic competency gained is reinforced, and becomes more permanent.

This cultural and linguistic learning can lead students to develop generalized cross-cultural skills with the assistance of international educators. We can provide valuable help to students doing research by asking them questions that will encourage them to realize that these skills transfer into other cultural situations. Often it requires simple queries: "What did you do to get this information? Did you have someone specific in the culture that gave you good advice? How did you find this person? What steps did you take when you succeeded in doing a piece of your research? When you did not succeed how did you figure out what went wrong? What did you do to try again? Beyond these basic questions, there are larger ones that can spur on student learning: "What did you learn from doing this project that would allow you to do another one in a completely different culture? How did you make sure your project was culturally appropriate? Did you think about making your project useful for local people? How would you share these results in the most effective way?" In posing these questions, we encourage students to examine the specific context of their research, and also to consider a meta-level analysis that places their research in a broader context. The hope is that students will see these skills in the wider global context, and that future cultural learning will be analyzed in a similar manner and transferred into other cross-cultural situations.

If we achieve this, then we have certainly met the highest goals of encouraging students to learn to transcend cultural differences in constructive ways and to adapt to differing cultural modes as appropriate. Student research abroad can be a powerful way to accomplish all types of cultural learning.

\section{Supporting Undergraduate Research Abroad}

Even with these benefits, not many undergraduate students undertake research opportunities abroad. Faculty may advise students that research in their chosen discipline is better done at home, given the resources of the home 
campus. Students may be told that their language skills are not strong enough or that they are simply not mature enough as scholars in their disciplines to conduct relevant research. Students may be encouraged to conduct research or participate in directed study, but not to do field work or participate in experiential learning. A student may be able to receive credit for an internship that requires a substantial paper, but not for an ethnographic study. Moreover, the very idea of conducting research may be daunting to some students.

Efforts should be made to advertise existing research opportunities abroad and to encourage new ideas for conducting research. If undergraduate research is endorsed by the highest academic officers of our institutions, our Presidents, Provosts and Academic Deans, faculty are more likely to provide encouragement and support, and then students will be more likely to pursue these options. International educators can assist these efforts by creating programs that offer research options, advertising such programs, and, most importantly, finding funding sources for such efforts. In order for students to take advantage of possible opportunities, it may be necessary to find ways to register students who might otherwise travel abroad independently (and thereby not be registered at their home institutions) in credit-bearing programs that would make them eligible for funding. The National Security Education Program David L. Boren Undergraduate Scholarships provides a model that allows advanced undergraduates with strong language skills to apply for funding for individually-arranged, supervised independent study.

International educators may also help by designing processes on the home campus that support student research abroad. Research can take many forms, from the use of original documents and artifacts in libraries, archives, and museums, to service-learning, conducting field work, joining a research group, conducting interviews, doing a creative project, or interning or volunteering for an organization. On-campus administrative processes should make clear to students what types of projects are eligible to receive credit. If a student expects to receive credit at their home institution, they need to be able to review easily the criteria for determining whether credit will be granted with the appropriate on-campus authority (e.g. academic dean, department head, or registrar). Receiving credit helps to motivate the student and to validate the undertaking; making the credit-granting process clear can make a big difference to students exploring these options. It also assures that there will be faculty input, if not throughout the project, at least in the determination of granting credit on the home campus. 
In designing programs abroad with research components, faculty involvement is essential. Indeed, faculty supervision and support can make or break such projects for students. Faculty supervisors on the home campus or abroad will be more likely to agree to support a student researcher if they feel that this is a recognized part of their teaching. The supervision of an independent study can be time-consuming. Do departments consider this supervision when assigning workloads? Is extra compensation provided? Should these financial concerns be addressed in the budgets of the abroad programs? Can students continue follow-up work with faculty after they return home?

Faculty supervision of student research abroad may follow various models. In some cases, research is an integral part of a study abroad program. Arrangements may be made to train the student on-site, perhaps as part of a course. The student conducts the research on-site, under the supervision of a resident director, or an on-site faculty member, and the course ultimately becomes a part of the student's academic record, along with all other courses taken abroad. Another model has a faculty member at the student's home institution supervising the student, along with some support given by a local faculty member. This model requires effective communication between the student and the faculty member on the home campus.

In both cases clear goals need to be established about the nature of the project, research methods, and the final product. Fortunately, many of these formats can follow timelines and processes already developed on the home campus. However, once in the host country, parameters may change. Students may discover new opportunities, or their original ideas and plans may not be feasible. The logistics of conducting research in an international setting may make it impossible to keep to the original goals.

In addition to guiding research and assessing the final product, faculty can serve in other important roles. They may introduce students to opportunities to submit their work for publication, present it at professional conferences, or compete for academic awards. Undergraduate research funding from the home institution might require a student to present their findings. Some institutions organize annual opportunities for students to give oral presentations or poster sessions during research fairs or conferences on campus. Others have a journal of student research. Resources and opportunities that are provided to students who conduct research on campus should also be extended to those whose work is done overseas. In many cases students may use the research conducted abroad as the foundation for a senior thesis. 
Students may choose to conduct independent research abroad. If students do research and are not enrolled in a program (e.g., during the summer) and have been encouraged to do so by their institution, have received funds from their institution, and will perhaps receive credit, their home institution should prepare them for the experience. Faculty and administrators should conduct seminars, orientation programs, and research methodology sessions to prepare students. Institutions should consider offering benefits to individual students that they would normally offer to students going abroad on registered study abroad programs (i.e., access to emergency services). By regularizing these aspects of going abroad, even to conduct independent research, institutions will be better able to track students who are conducting research abroad. At the minimum, students going abroad independently should be directed to information sources on health, safety, and security preparations when traveling to the host country. Additionally, students should be made aware of any legal issues related to doing research, and have their proposals vetted through the usual campus channels such as institutional review boards.

\section{O u t c o m es of 5 t udent Rese a r c h}

Little data exists on how many students conduct research abroad, or on how this experience affects their academic work when they return to campus as well as their career decisions after graduation. Currently the national data on study abroad from the Institute of International Education's annual Open Doors report documents only participation in credit-bearing programs. No statistics are kept on the numbers of students conducting research abroad who will not receive credit for their research.

Among the questions this lack of data raises are: Are these students more likely to attend graduate school in their major discipline and to look for opportunities to conduct research abroad? Are they more likely to pursue independent research in sites that are less common as study abroad destinations? If they conducted research in a foreign language, are they more likely to study this language at an advanced level?

The Lincoln Commission articulates the need for more in-depth international educational experiences, of which research can play an important part:

An understanding of the diverse cultures of the world, especially those of developing countries, should be an essential component of the 21st century education of our nation's students. Direct exposure to foreign languages and other aspects of these cultures 
can best be achieved through a meaningful study abroad experience. Broader global awareness among America's future leaders will, in turn, lead to more effective U.S. foreign policy, greater security from terrorism and economic resilience in the increasingly competitive world of trade.

The research benefits discussed above mesh well with the current national interests that call for broader global awareness, and international educators should seriously consider designing and supporting research opportunities as one of their efforts to increase such competencies. Conducting research abroad can be one of the most personally satisfying parts of a student's undergraduate academic career. These undertakings can also be frustrating and fraught with difficulties unless there is good planning and communication with a students' academic advisors. International educators can assist in making these opportunities as effective, safe, and rewarding as possible. Faculty and administrators should look for ways to help students overcome the potential barriers to a successful experience, including the credit-approval process, organizing faculty supervision, and accessing information about opportunities, as well as funding. Since undergraduate student research abroad can lead to improved linguistic competence, cross-cultural skills, cultural competence, and disciplinary knowledge, we should do everything we can to develop and promote it.

Mell C. Bolen

Brown University

Pat Martin

University of Pennsylvania 